\title{
Academic, Psychological and Social effects of University Closure among Health Profession Students during an Outbreak of COVID-19 at Alzaeim Alazhari University 2020
}

\author{
Amal Mohammed Hamid ${ }^{1 *}$, Amel Ahmed Hassan ${ }^{1}$, Nadia Ahmed Mohamed ${ }^{3}$, Muneera Mohamed Hamad ${ }^{4}$, Tayseer \\ Ahmed Hassan ${ }^{5}$

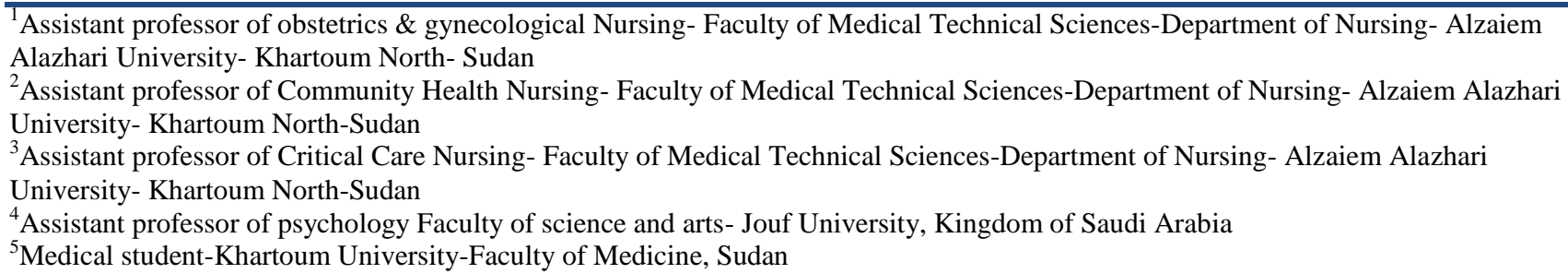

Article History
Received: 22.01 .2021
Accepted: 04.03 .2021
Published: 20.03 .2021

Journal homepage: https://www.easpublisher.com

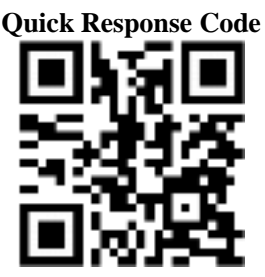

\begin{abstract}
Background: The coronavirus crisis has challenged higher education institutions in many new and unexpected ways a growing number of universities across the world have either postponed or canceled all activities and precautionary measures have been taken to safeguard students and staff members from highly infectious diseases. Aim: To assess the effects of university closure during the outbreak of COVID-19 on the academic, psychological, and social status of health professional students. Methods: A descriptive cross-sectional study was conducted at Alzaiem Alazhari University among health profession students from April to July 2020. The subjects of the study who amounted to 298 were selected using the convenience sampling technique. The data were gathered through an electronic questionnaire and analyzed using SPSS software. The results were displayed as frequency and percentage, a statistical test was used and the level of statistical significance was calculated by chi-square and $\mathrm{P}$ values $(\leq 0.05)$. Results: There was a significant effect of university closure during the outbreak of COVID-19 outbreak on academic performance. $(80.5 \%)$ of the participants did not study and review their previous courses during the closing period of the university, and also on the psychological well-being of the candidates. (92\%) became anxious and worried about their academic and professional future and on social status, as (89\%) increased the number of hours spent on social media during university closures. all p-values were less than 0.05 . Conclusion: The study concluded that university closure during the outbreak of COVID-19 had a negative impact on the academic performance and psychological well-being of health profession students.

Keywords: COVID-19, closure, academic, psychological, students.
\end{abstract}

Copyright ( 12021 The Author(s): This is an open-access article distributed under the terms of the Creative Commons Attribution 4.0 International License (CC BY-NC 4.0) which permits unrestricted use, distribution, and reproduction in any medium for non-commercial use provided the original author and source are credited.

\section{INTRODUCTION}

The novel coronavirus disease 2019 (COVID19) emerged at the end of December 2019 in Wuhan, China [1]. The initial outbreak of COVID-19 in Wuhan spread rapidly, affecting other parts of China. The authorities in Wuhan took unprecedented steps and locked down the city on January 23, 2020, to lower the risk of further disease transmission [2]. Within a few weeks, cases of COVID-19 been detected in several other countries and soon become a global threat [3]. The World Health Organization (WHO) declared the coronavirus epidemic a pandemic [4]. As of July 26, the virus had spread to 193 countries and infected more than16.100.905 patients, resulting in more than 645.485 deaths. The 1st case was reported in Sudan on the 13th of March 2020 and a partial curfew was declared on March 31st. of March from 6:00 pm to 6:00 am the following day. Up to 27 of July 27, there were 11.385 confirmed cases with 717 deaths [5]. To avoid the spread of the disease, several countries have imposed travel restrictions (both within and outside) to respond to COVID-19. Several steps are being taken by public health advocates and government leaders, including social distancing, self-isolation, or quarantine, improving health facilities for disease control, and 
urging people to work at home [6]. The COVID-19 pandemic has impacted educational systems around the world, contributing to the almost complete closure of schools, universities and colleges [7]. 150 countries have closed schools and educational facilities worldwide as of March 25, affecting over 80 percent of the student population of the country. Several countries have adopted regional school closures, which may be national in nature [8]. In Sudan, all universities and colleges were closed on March 21, 2020 as one measure to prevent disease spread. A large number of studies have been conducted on the closure of educational institutions as a safety measure to reduce the spread of infectious diseases in the community by breaking important chains of transmission [9]. Universities have moved rapidly to transition various courses and programs from face-to-face to online delivery mode [10], but in Sudan, due to lack of preparedness and weak infrastructure, online learning during COVID-19 has become a stumbling block for both students and educators. It is anticipated that the continued spread of the pandemic, strict isolation measures and delays in starting schools, colleges and universities across the nation would affect the psychological and social status of university students. Students studying in health professions education, which is composed of different specialties, may be more affected by university closures because their specialties rely mainly on clinical training in health facilities and in labs, which is difficult to conduct during this pandemic. However, no detailed study on the impact of the university closure on the academic, psychological and social status of university students facing the pandemic, to the best of our knowledge, has been conducted in Sudan.

In this study, the authors tried to answer the question: Is there any potential impact of university closure during the severe COVID-19 outbreak on the academic, psychological, and social status of university students?

The purpose of this study was to assess the impact of university closure during the outbreak of
COVID-19 on the academic, psychological and social status of health professional students at Alzaeim Alazhari University and to determine the correlation between socio-demographic characteristics and academic, psychological, and social effects.

\section{Materials ANd Methods}

A descriptive cross-sectional study was conducted at Alzaiem Alazhari University on Bahri campus, where all the medicine and health sciences faculties have been established The six faculties in the campus were Medicine, Dentistry, Public health, Radiology Sciences \&Medical imaging, Medical laboratory sciences, and faculty of medical-technical sciences (composed of five departments Nursing, Anesthesia, Midwifery, Physiotherapy, Nutrition \&Diet therapy) The total number of students in all faculties was 4000 . The present study was conducted during the academic year 2020 from April to July. The study sample was selected by convenience sampling among the health profession students who agreed to participate in the study and had internet access; the sample size was calculated using software by considering the total population of students during the study period; power was kept at $80 \%$, response distribution was $50 \%$, the confidence interval was set at $95 \%$ and the margin of error was set at $5 \%$. The results of the calculation were 350 students from different levels, and $298(85 \%)$ of the sample responded. The study was approved by the Faculty Research and Ethics Committee and informed consent was obtained from all participants. The data were gathered through an electronic questionnaire developed by the researchers at Google form document, which contained demographic characteristics of participants and closed questions regarding their academic, psychological and social status during university closure due to the COVID 19 crisis. The data were analyzed using SPSS and the results were displayed in frequency and percentage for demographic characteristics and a statistical test was used for closed questions. The level of statistical significance was calculated using chi-square and P-value $(\leq 0.05)$.

\section{RESUlTS}

Table-1: Distribution of the participants according to their demographic characteristics $(n=298)$

\begin{tabular}{|l|l|l|l|}
\hline Demographic Characteristics & Frequency & Percent \\
\hline \multirow{5}{*}{ Age } & $15-20$ & 139 & $46.6 \%$ \\
\cline { 2 - 4 } & $21-25$ & 154 & $51.7 \%$ \\
\cline { 2 - 4 } & $26-30$ & 3 & $1.0 \%$ \\
\cline { 2 - 4 } & $31-35$ & 2 & $0.7 \%$ \\
\hline Sender & Male & 46 & $15.4 \%$ \\
\cline { 2 - 4 } & Female & 252 & $84.6 \%$ \\
\cline { 2 - 4 } & Nursing & 53 & $17.8 \%$ \\
\cline { 2 - 4 } & Anesthesia & 75 & $25.2 \%$ \\
\cline { 2 - 4 } & Midwifery & 11 & $3.7 \%$ \\
\cline { 2 - 4 } & Physiotherapy & 49 & $16.4 \%$ \\
\cline { 2 - 4 } & Public health & 5 & $1.7 \%$ \\
\cline { 2 - 4 } & Radiology sciences \&medical imaging & 45 & $15.1 \%$ \\
\cline { 2 - 4 } & Medical laboratory sciences & 8 & $2.7 \%$ \\
\cline { 2 - 4 } & Medicine & 7 & $2.3 \%$ \\
\cline { 2 - 4 } & Dentistry & 30 & $10.1 \%$ \\
\cline { 2 - 4 } & Nutrition \&diet therapy & 15 & $5.0 \%$ \\
\hline
\end{tabular}


Table-1 presents the demographic characteristics, it is reflected that half of the participants aged between (21-25 years) (51.7\%) and more than two-fifth of participants aged between (15-20) (46.6\%), this finding is corresponding with the normal distribution of study age in Sudan which considers that the majority of university students age between $15-25$ years. In relation to participant's gender, most of them were females $(84.6 \%)$ and this is similar to the general situation in higher education in Sudan which reveals that female numbers are more than males mainly in applied colleges. Concerning Specialty, the response of all participants was less than a quarter, except for anesthesia (25.2\%), perhaps due to technical problems during the distribution of the electronic questionnaire and poor internet access during the data collection period.

Table-2: Distribution of the participants according to their academic, psychological, and Social status $(n=298)$

\begin{tabular}{|c|c|c|c|c|}
\hline Status & Items & yes\% & No\% & $\begin{array}{l}\text { p. } \\
\text { value }\end{array}$ \\
\hline \multirow{4}{*}{ Academic } & $\begin{array}{l}\text {-Do you think you can go back to university again without feeling overwhelmed or } \\
\text { making an extra effort to focus? }\end{array}$ & 27.2 & 72.8 & \multirow[b]{4}{*}{0.000} \\
\hline & -Do you study during the closing period of the university or review previous courses? & 19.5 & 80.5 & \\
\hline & $\begin{array}{l}\text {-In the event that you become a remote/ online student, can you study seriously and for } \\
\text { the same number of hours as during the direct contact study period? }\end{array}$ & 34 & 66 & \\
\hline & -Did you attend any of the online courses during the closing period? & 22 & 78 & \\
\hline \multirow[t]{2}{*}{ Psychological } & $\begin{array}{l}\text {-Do you think that the large quantity of news circulating on the media about the } \\
\text { Corona pandemic increases your sense of tension, anxiety, and frustration }\end{array}$ & 66 & 34 & \multirow[b]{2}{*}{0.000} \\
\hline & $\begin{array}{l}\text {-Have you become more concerned and worried about your academic and professional } \\
\text { future after the university closed due to the Corona pandemic? }\end{array}$ & 92 & 8 & \\
\hline \multirow{5}{*}{ Social } & $\begin{array}{l}\text {-Do you think that the closure of the university due to the Corona pandemic has } \\
\text { affected your social activities and your effective communication with those around } \\
\text { you? }\end{array}$ & 81 & 19 & \multirow{5}{*}{0.000} \\
\hline & $\begin{array}{l}\text {-Do you think the lockdown has positive effects on your relationship with the small } \\
\text { family members? }\end{array}$ & 74 & 26 & \\
\hline & $\begin{array}{l}\text {-Do you think that your social relationships (your friends, colleagues, relatives) will be } \\
\text { stronger after the social distancing caused by the Corona pandemic }\end{array}$ & 66 & 34 & \\
\hline & $\begin{array}{l}\text { - Have you refrained from communicating with your friends and classmates since the } \\
\text { university closed? }\end{array}$ & 30 & 70 & \\
\hline & $\begin{array}{l}\text {-Do you think that the closure of the university due to the Corona pandemic has } \\
\text { increased the number of hours you spend on social media? }\end{array}$ & 89 & 11 & \\
\hline
\end{tabular}

Table-2 shows that nearly three-quarters $(72.8 \%)$ of the participants felt overwhelmed and may need to do extra effort to focus on their studies when they return to the university. The majority of participants $(80.5 \%)$ did not study and review their previous courses during the university closing period; about two-thirds of participants $(66 \%)$ could not study seriously and for the same number of hours in a remote study program as compared to the direct contact study program. More than three-quarters $(78 \%)$ of the participants did not attend any online courses during the closing period. These findings reflect that there is a negative effect of university closure on the academic status of the students and there is a significant difference among the proportions in the academic status questions, with a p-value of 0.000). In terms of psychological status, two-thirds of the participants $(66 \%)$ revealed that the large quantity of news circulating on the media about the coronavirus pandemic increased their sense of tension, anxiety, and frustration and most of the participants $(92 \%)$ became more concerned and worried about their academic and professional future after the university closed due to the coronavirus pandemic. From the above findings, the bad news about COVID-19 makes students more anxious as well as it increases anxiety towards the future career as a result of this pandemic, that according to the $\mathrm{p}$ value of chi-square is $(0.000)$ which indicates a significant difference among the proportions in the psychological status questions. Social status The majority $(81 \%)$ of the participants thought that the closure of the university due to the Corona pandemic affected their social activities and effective communication with those around them, near to three quarters $(74 \%)$ of participants thought that the lockdown had positive effects on their relationship with their small family members, two-thirds of participants (66\%) thought that their social relationships with their friends, colleagues, and relatives would be stronger after the social distancing caused by the Coronavirus pandemic, near to three quarters $(70 \%)$ of participants cannot refrain from communicating and contacting with their friends and classmates after the university closed and most of the participants ( $89 \%$ ) increased the number of hours spent on social media during university closure; all $\mathrm{p}$ values indicate a significant difference among proportions of the questions through the social status. 
Table-3: Description of the relationship between age and academic and Social status $(n=298)$.

\begin{tabular}{|c|c|c|c|c|c|c|c|}
\hline \multicolumn{2}{|c|}{ Variable } & \multicolumn{2}{|c|}{$\begin{array}{l}\text { Academic status } \\
\text {-Do you think you can go back to school } \\
\text { again without feeling overwhelmed or } \\
\text { making an extra effort to focus? }\end{array}$} & \multirow{4}{*}{$\begin{array}{l}\text { p. } \\
\text { value } \\
.036\end{array}$} & \multicolumn{2}{|c|}{$\begin{array}{l}\text { Social status } \\
\text {-Did you refrain from communicating with } \\
\text { your friends and classmates after the } \\
\text { university closed? }\end{array}$} & \multirow[t]{2}{*}{$\begin{array}{l}\text { p. } \\
\text { value }\end{array}$} \\
\hline \multirow{7}{*}{ Age } & Age groups & yes & No & & yes & No & \\
\hline & $15-20$ & $46(15.4 \%)$ & $93(31.2 \%)$ & & $30(10.1 \%)$ & $109(36.6 \%)$ & \multirow{6}{*}{0.008} \\
\hline & & & & & & & \\
\hline & $21-25$ & $32(10.7 \%)$ & $122(40.9 \%)$ & & $55(18.5 \%)$ & $99(33.2 \%)$ & \\
\hline & $26-30$ & $2(0.7 \%)$ & $1(0.3 \%)$ & & $1(0.3 \%)$ & $2(0.7 \%)$ & \\
\hline & $31-35$ & $1(0.3 \%)$ & $1(0.3 \%)$ & & $2(0.7 \%)$ & $0(0.0 \%)$ & \\
\hline & Total & $81(27.2 \%)$ & $217(72.8 \%)$ & & $88(29.5 \%)$ & $210(70.5 \%)$ & \\
\hline
\end{tabular}

Table-3 shows that there is a significant association between age and academic status and that participants feel overwhelmed and may need to do extra effort to focus on their studies; the $(21-25)$ ( 40.9\%) age group is found to be more affected $\mathrm{p}$. value of chi $=$
0.036 ; there is also a significant association between age and social status, especially age group (15-20) $(36.6 \%)$ did not refrain from communicating with their friends and classmates after the university closed $\mathrm{p}$. value of chi $=0.008$.

Table-4: Description of the relationship between Gender and Psychological status ( $n=298)$

\begin{tabular}{|c|c|c|c|c|c|}
\hline Variables & \multicolumn{4}{|c|}{$\begin{array}{l}\text { Psychological status } \\
\text { Have you become more concerned and anxious about your academic and professional future after the } \\
\text { university closed due to the Corona pandemic? }\end{array}$} & $\begin{array}{l}\text { P. } \\
\text { Value }\end{array}$ \\
\hline \multirow[t]{4}{*}{ Gender } & Male & & Female & & \multirow{4}{*}{.052} \\
\hline & Yes & No & Yes & No & \\
\hline & 39 & 7 & 235 & 17 & \\
\hline & $13.1 \%$ & $2.3 \%$ & $78.9 \%$ & $5.7 \%$ & \\
\hline
\end{tabular}

Table-4 shows that there is a significant association between gender and psychological status in the degree of participants' anxiety about their academic and professional future after the university closure due to the Coronavirus pandemic and that females were found to be more anxious $(78.9 \%)$, p value of chi $=0.052$.

Table-5: Describes the relationship between participants' specialty and academic and social status $(n=298)$

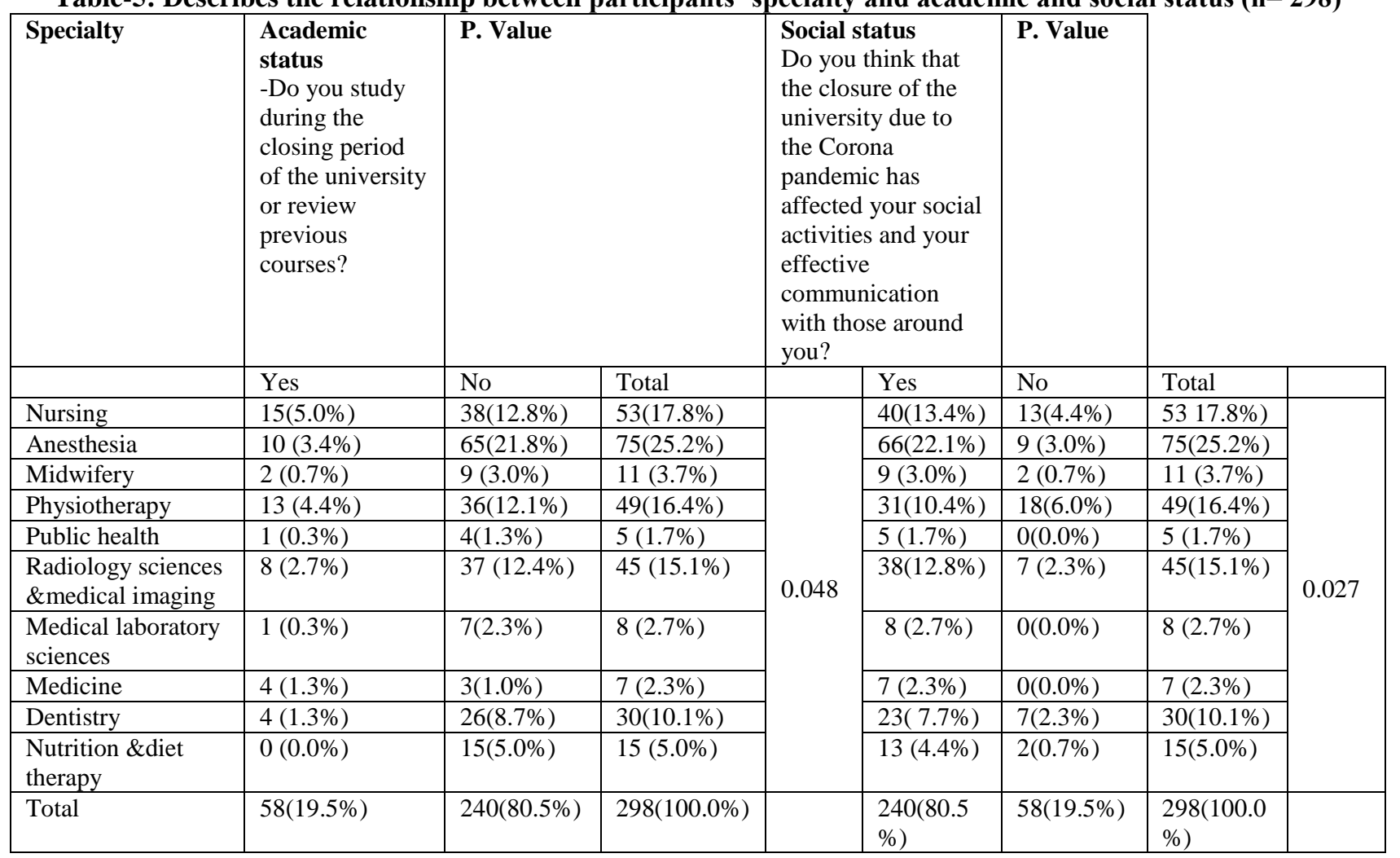


Table-5 describes that there is a significant association between specialty and academic status regarding study during the university closing period review of previous courses $(80.5 \%)$ of the participants from different specialties Said "No," p. value of chi $=$ 0.048 , also there is a significant association between Specialty and social status as an effect of university closure due to the Corona pandemic on participants' social activities and effective communication with their surroundings. $(80.5 \%)$ of the participants from different specialties indicated that it could affect the $\mathrm{p}$ value of chi $=0.027$.

\section{DISCUSSION}

This survey indicates that more than $(66 \%)$ of the participants were affected negatively by university closures during the outbreak of COVID-19 in their academic part. This result appears to be due to the university's plan to shift from face-to-face to online classes so that many teachers and students have been excited by the move to the online delivery mode. To them, online teaching is a new model of teaching and there is a lack of training on the use of online learning platforms among faculty members and students. Furthermore, computers and IT equipment at home are now in heavy demand from parents and students who have to work from home. Thus, working at home is a difficult task for students. This finding is similar to a study done by Pradeep Sahu, which revealed that the COVID-19 pandemic may have a serious impact on the careers of these years' university graduates, because they are experiencing major interruptions in teaching and assessment in the final part of their studies [11].

The dramatic rise in infected cases worldwide has created a sense of doubt and uncertainty about what is going to happen. The present study displays that the majority of students have experienced anxiety because of the COVID-19 outbreak and its impacts, especially female students who are found to be more anxious, this may be due to that females are more concerned about feeling isolated or not being able to reach family and friends in case of need, than the males. University students' anxiety about COVID-19 might also be related to the effect of the virus on their studies [12] and future employment. On the other hand, the students' anxiety may have been caused by the gradually increasing distances between people resulting from quarantine.

These results are consistent with many studies that have suggested that public health emergencies can have many psychological effects on college students, which can be expressed as anxiety, fear, and worry [13].

The social relationships of individuals are likely to be affected by crises in different ways. Social relationships are a conduit for social support [14]. In our study on social status. The majority of participants thought that the closure of the university due to the coronavirus pandemic has affected their social activities and effective communication with those around them, positively and the lockdown had positive effects on their relationship with their members.

\section{LIMITATIONS}

The present study has some limitations. For example, an online survey makes it difficult to generate random samples because the respondents are only those who use the Internet. Such sampling weakens the generalizability of the study findings, and the survey participants did not have the opportunity to ask clarifying questions.

\section{Conclusions}

University closure during the outbreak of COVID-19 has had negative impacts on the academic and psychological status of health profession students manifested in the intensified feeling of anxiety and difficulties in academic performance, but there were favorable social effects among the students. Sociodemographic characteristics significantly affected students' academic, psychological, and social status. It is suggested that proper counseling services should be available to support the mental health and well-being of students and that faculty members should embrace technology and pay careful attention to student experiences to make the learning rich and effective.

\section{ACKNOWLEDGMENTS}

All the authors acknowledge the enthusiasm with which the students of the Faculties of Medical and Health Sciences at Alzaiem Alazhari University participated in the study.

Funding: There was no financial support and sponsorship for the study

Conflict of interests: The authors declare that there are no conflicts of interest regarding the publication of this paper.

\section{REFERENCES}

1. Chahrour, M., Assi, S., Bejjani, M., Nasrallah, A. A., Salhab, H., Fares, M., \& Khachfe, H. H. (2020). A bibliometric analysis of COVID-19 research activity: a call for increased output. Cureus, 12(3):e7357.

2. Xiang, Y. T., Yang, Y., Li, W., Zhang, L., Zhang, Q., Cheung, T., \& Ng, C. H. (2020). Timely mental health care for the 2019 novel coronavirus outbreak is urgently needed. The Lancet Psychiatry, 7(3), 228-229.

3. Spina, S., Marrazzo, F., Migliari, M., Stucchi, R., Sforza, A., \& Fumagalli, R. (2020). The response of Milan's Emergency Medical System to the COVID-19 outbreak in Italy. The Lancet, 395(10227), e49-e50. 
4. WHO. Coronavirus disease (COVID-19) pandemic. (2020). Accessed: March 20, 2020: https://www.who.int/emergencies/diseases/novelcoronavirus-2019

5. Coronavirus COVID-19 global cases by the Center for Systems Science and Engineering (CSSE) at Johns Hopkins University (JHU). (2020). Accessed: July 26, 2020, https://coronavirus.jhu.edu/map.html

6. Bedford, J., Enria, D., Giesecke, J., Heymann, D. L., Ihekweazu, C., Kobinger, G., ... \& Wieler, L. H. (2020). COVID-19: towards controlling of a pandemic. The lancet, 395(10229), 1015-1018.

7. UNESCO (2020-03-04). "Education: From disruption to recovery". UNESCO. Retrieved 27 July 27, 2020

8. UNESCO. COVID-19 Educational disruption and response. (2020). Accessed: July 27, 2020. https://en.unesco.org/themes/educationemergencies/coronavirus-school-closures.

9. Kawano, S., \& Kakehashi, M. (2015). Substantial impact of school closure on the transmission dynamics during the pandemic flu H1N1-2009 in Oita, Japan. PloS one, 10(12), e 0144839.

10. Gewin, V. (2020). Five tips for moving teaching online as COVID-19 takes hold. Nature, 580(7802), 295-296.

11. Sahu, P. (2020). Closure of universities due to coronavirus disease 2019 (COVID-19): impact on education and mental health of students and academic staff. Cureus, 12(4).

12. Cornine, A. (2020). Reducing nursing student anxiety in the clinical setting: An integrative review. Nursing education perspectives, 41(4), 229-234.

13. Mei, S. L., Yu, J. X., He, B. W., \& Li, J. Y. (2011). Psychological investigation of university students in a university in Jilin province. Med Soc (Berkeley), 24(05), 84-86.

14. COVID, R. R. (2020). and mental health: a review of the existing literature. East Asian Arch. Psychiatry, 52.

Cite This Article: Amal Mohammed Hamid et al (2021). Academic, Psychological and Social effects of University Closure among Health Profession Students during an Outbreak of COVID-19 at Alzaeim Alazhari University 2020. EAS J Nurs Midwifery, 3(2), 57-62. 